\title{
A comparison of killer and nonkiller rats
}

\author{
B. MICHAEL THORNE, TAYLOR WALLACE, and IRA DANZIG \\ Mississippi State University, Mississippi State, Mississippi 39762
}

\begin{abstract}
Two experiments were performed on Long-Evans rats. The first study was designed to evaluate possible differences in muricidal behavior between killer and nonkiller rats following $O B$ lesions. No significant differences in muricidal behavior were found after OB damage in either group. Experiment 2 examined the behavior of killer and nonkiller rats on reactivity to handling, openfield activity divided into the number of squares traversed and rearing, learning of a visual discrimination task, and learning of an olfactory discrimination task. Killers were found to be less reactive to handling, while exhibiting greater horizontal activity in the open-field test. No other differences were found.
\end{abstract}

Despite the fact that an enormous amount of research has been focused on the muricidal response of the domestic rat, it is surprising that more effort has not been devoted to comparing killer and nonkiller rats. The few comparisons that have been made have yielded contradictory results.

One possible difference between killers and nonkillers lies in their reaction to olfactory bulb (OB) damage. Thus, $O B$ damage has been found to increase muricide in nonkillers (Karli, Vergnes, \& Didiergeorges, 1969; Malick, 1970; Thorne, Aaron, \& Latham, 1973, 1974), while the same damage in killers has been reported to have the opposite effect (Bandler \& Chi, 1972; Thompson \& Thorne, 1975).

When comparing killer and nonkiller rats on behavioral indexes other than the killing response, some researchers have noted differences while others have not. For example, Nováková, Flandera, and Sandritter (1974) found killer rats to be "more excitable." They based their interpretation on the fact that killer rats were less able to habituate exploratory behavior and exhibited more horizontal activity in an exploration test. In addition, the amount of time taken to acquire an auditory conditioned reflex was greater in killer rats while their retention was poorer.

Vergnes, Boehrer, and Karli (1974) also reported greater emotionality in killers than in nonkillers. However, careful examination of their results reveals that five of six comparisons between killer and nonkiller rats were not significant. In fact, the only behavioral measure on which a significant difference was found was the number of boluses deposited during the second of two open-field tests. Thus,

This research was performed by the third author in partial fulfillment of the requirements for the MS degree in Psychology at Mississippi State University. The research was in part supported by an institutional grant awarded to MSU by NSF. Send reprint requests to: B. Michael Thorne, Drawer PF, Mississippi State, Mississippi 39762. rather than supporting Nováková et al. (1974), the study by Vergnes et al. provides greater evidence for a lack of differences between killers and nonkillers than it does for differences. Similarly, Knutson and Hynan (1973) found no difference between killers and nonkillers with respect to shock-induced fighting.

In addition, Thorne, Patterson, and Topping (1975) found that killer rats and nonkillers did not differ in terms of handling characteristics, number of squares traversed in an open field, or learning and retention of a discrimination problem motivated by escape from footshock. In fact, the only reliable difference between killers and nonkillers was that killers exhibited more rearing behavior in the open field than nonkillers. By contrast, Nováková et al. (1974) reported more vertical activity (rearing) in nonkillers.

Thorne et al. (1975), however, used animals that had been tested for muricide with wild field mice, while it is virtually certain that Nováková et al. (1974) did not. Thorne and Thompson (1976) found that wild mice cause a much higher percentage of killing in rats than do less active domestic mice; i.e., many rats are induced to kill by wild mice that would not kill if exposed to a domestic mouse. Thus, it is possible that one explanation for the discrepancy between Thorne et al. and Nováková et al. is that there are behavioral differences between "induced" killers and "natural" killers, with induced killers being behaviorally similar to nonkillers.

In an attempt to further investigate these controversies, two experiments were performed. The first one was designed to study the effect of $O B$ damage upon muricidal behavior in killer and nonkiller rats. The second experiment was undertaken to compare natural killers and nonkillers on behavioral measures such as handling characteristics, activity in an open field, learning of a visual discrimination task, and the learning of an olfactory discrimination task. 


\section{EXPERIMENT 1}

In order to determine the changes in muricidal behavior as a result of $O B$ damage, a large number of rats were tested for muricidal tendencies. Some of the killers and some of the nonkillers were subjected to OB removal and, following a recovery period, were retested. Comparisons were made with unoperated killers and nonkillers.

\section{Method \\ Subjects \\ The subjects were 100 80-90-day-old male Long-Evans rats obtained from Blue Spruce Farms (Altamont, New York). All animals were received in one shipment at approximately 23 days of age and were housed in group cages until $24 \mathrm{~h}$ prior to testing, at which time they were housed individually in cages measuring $17.78 \times 25.40 \times 17.78 \mathrm{~cm}$. Ad-lib food and water conditions were maintained at all times, and the subjects were not gentled prior to testing.}

\section{Procedure}

Preliminary testing. The preliminary screening procedure consisted of a muricidal test in which an albino mouse was placed into the cage of a rat. The animals were observed continuously for $30 \mathrm{~min}$ while the latency to kill and the incidence of muricide were recorded. After $30 \mathrm{~min}$, any live mice or the remains of dead ones were removed.

On the basis of the 30 -min test, 17 rats were found to be killers. Ten of these rats were randomly selected and assigned to Group KOB (killers given OB damage). Ten rats of the remaining 83 that did not kill were randomly selected and assigned to Group NKOB (nonkillers given $O B$ damage). The remaining 7 killers were assigned to Group KNO (killers given no operations), and 11 nonkillers were assigned to Group NKNO (nonkillers given no operations).

Surgery. The subjects were anesthetized with chloral hydrate, had their heads clipped, and were given an intramuscular injection of Duricilin $(.2 \mathrm{cc})$. The animal's head was then secured in the headholder of a Baltimore stereotaxic instrument with a horizontal orientation. After making an incision in the scalp, a section of the skull overlying the olfactory bulbs was removed with a dental drill and mastoid rongeurs. Then the olfactory bulbs rostral to the frontal area were removed by subpial aspiration. Finally, the scalp incision was closed with stainless steel autoclips and the rat was placed into its cage to recuperate.

Postoperative testing. Following surgery, the animals given OB lesions were given 5 days to recover, and all animals in the four groups were retested for muricidal behavior in a manner duplicating that described for preliminary testing.

Histology. At the conclusion of testing, all lesioned subjects were sacrificed with an overdose of Nembutal. The subjects were then decapitated, the tops of the skulls were removed, and the entire heads put into Formalin for at least 1 week prior to removal of the brains. The extent of damage was assessed by comparison to line drawings using the method described by Thorne et al. (1973).

\section{Results and Discussion}

Histological analysis showed that there was no significant difference in the extent of damage to the olfactory bulbs for the two OB groups (NKOB, KOB). The average extent of damage was approximately $91 \%$ rostral to the frontal region.

The results of the muricide test are summarized in Figure 1. Although 4 of 10 rats began to kill fol-

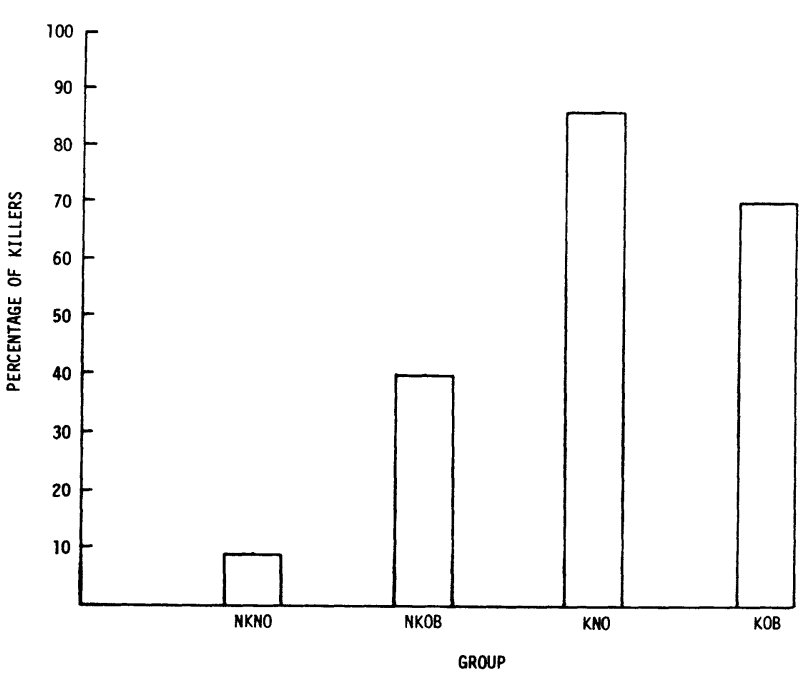

Figure 1. Percentage of animals in each group exhibiting mousekilling behavior.

lowing OB removal, in comparison with Group NKNO the increase was not significant (Fisher exact probability test, $\mathrm{p}=.1259$ ). Failure to obtain a significant increase in muricide following $\mathrm{OB}$ damage disagrees with most previous research (Karli et al., 1969; Malick, 1970; Thorne et al., 1973, 1974).

The percentage of killers in Group NKOB $(\mathbf{4 0 \%})$ was far less dramatic than in several previous reports [e.g., Thorne et al. (1973) found $90 \%$ killers in a group given comparable operations]. A possible explanation for this difference is that rats in the present study were given a muricide test prior to the operation, while animals in the Thorne et al. study were naive. It has been demonstrated that previous exposure to mice in a nonkilling situation decreases the probability of subsequent killing (Denenberg, Paschke, \& Zarrow, 1968; Myer, 1969).

Additionally, OB damage had little effect on the incidence of killing in established killers, although a smaller percentage of Group KOB animals killed than did Group KNO rats $(86 \%$ vs. $70 \%)$. This finding disagrees with the report by Bandler and Chi (1972).

Killer and nonkiller rats did not significantly differ in their responses to OB lesions. Although a higher percentage of animals in Group KOB killed than did those in Group NKOB ( $70 \%$ vs. $40 \%)$, this is not unexpected since Group KOB animals had had previous killing experience. In previous research (Myer, 1971; Myer \& White, 1965) killing has been shown to be reinforcing. Thus, performance of the response increases the probability of its occurrence in subsequent tests.

Although there was a significant difference between Groups NKNO and KNO $(p<.05)$, this was expected, since the criterion used to group these animals (muricide) was the ultimate criterion for 
their difference. This merely serves as an index of consistency, showing that nonkillers remain nonkillers after one test and killers continue to kill.

Comparisons of latencies revealed a significant difference between Groups NKOB and KOB, with rats in Group KOB killing more rapidly (MannWhitney $U=4, p=.036$ ). The median latencies were, for Group KOB, $35 \mathrm{sec}$, and for Group NKOB, $292 \mathrm{sec}$. The simplest explanation for this difference is that the animals in Group KOB had had more experience in killing than the rats in Group NKOB. It has been shown that practice produces a decrease in the latency to kill (Myer, 1971).

Comparisons of the latencies of Group KNO's first test with the latencies of its second test failed to yield a significant difference. Nor did a comparison of Group KOB's latencies on Tests 1 and 2 yield a significant difference. This would seem to contradict the findings of Myer (1971), who found killing latencies to decrease markedly over successive kills. However, Myer used median latencies of killers over a series of 10 kills. It is possible that, given 10 tests, the killers in the present study would have shown a significant decrease in killing latency.

\section{EXPERIMENT 2}

This experiment was undertaken to further examine whether or not differences in behavior other than muricide exist between killers and nonkillers. Essentially, the present experiment is a replication of much of the Thorne et al. (1975) study and a portion of the McCabe and Thorne (1976) report. In Thorne et al. and McCabe and Thorne, the killer rats used for comparison with nonkillers had been induced to kill either by exposure to wild mice or by food deprivation, respectively. By contrast, we compared natural killers and nonkillers in this experiment, i.e., rats which were initially tested with domestic mice and were not food deprived. The present study also differs from previous reports in that a comparison of olfactory learning ability between killers and nonkillers was made. Thus, killers and nonkillers were compared on measures of handling characteristics, activity in an open field, learning of a visual discrimination task, and the learning of an olfactory discrimination task.

\section{Subjects \\ Method \\ The subjects consisted of six of the seven rats in Group KNO of Experiment 1 and six rats chosen randomly from Group NKNO of Experiment 1. All subjects were singly housed in cages measuring $17.78 \times 25.40 \times 17.78 \mathrm{~cm}$ and were given ad-lib food and water prior to olfactory discrimination training.}

\section{Apparatus}

The apparatus used to assess locomotor activity was an openfield box measuring $76.2 \times 76.2 \times 25.4 \mathrm{~cm}$. The entire box was painted flat black, and the floor was divided by white lines into 25 equal squares. Wire mesh covered the top.

The visual discrimination apparatus was a Thompson-Bryant two-choice box from which the choice chamber had been removed, leaving only a startbox and a goalbox. The startbox had a grid floor through which footshock could be administered to motivate the animal. A Plexiglas door separated the start area from a 7.6-cm grid in front of two openings into the goalbox.

The olfactory discrimination apparatus was a modified WGTA described fully by Rollin, Shepp, and Thaller (1963). Stimulus cards were made from $5 \times 5 \mathrm{~cm}$ pieces of posterboard pasted on $5 \times 5 \mathrm{~cm}$ bases of plywood. A pair of gray cards was used to train the animal to expose the reward, while a white-black (W-B) pair was used for discrimination testing. The white card was painted with flat white enamel and the black card with flat black enamel. It has been demonstrated that in the small animal WGTA virtually all rats learn an olfactory discrimination when both visual cues and olfactory cues are relevant (Thorne \& O'Brien, 1971). Throughout discrimination training, the W-B cards were repainted approximately once every 2 weeks and were cleaned with water between animals.

\section{Procedure}

All animals were given 5-day tests of handling characteristics and open-field activity. Emotionality was rated on a 5-component scale modified from the scale reported by King (1958). The components were as follows: (1) reaction to a pencil near the perioral region, (2) reaction to a pencil tap on the flank, (3) ease of capture from the home cage, (4) resistance to handling, and (5) amount of vocalization during testing. Each component was rated on a 4-point scale (0-3), and each animal was given a daily total based on the sum of the ratings on the five components. Further details of testing may be found in Thorne et al. (1973).

Immediately following the rating of handling characteristics, each animal was placed into the center of the open-field apparatus, and the number of squares traversed in a 1-min period was recorded. During the open-field test, all squares entered or crossed by the rats' hind feet were counted. In addition, the number of times the animals reared (i.e., assumed a bipedal posture) was noted.

On the fourth day following completion of the handling and activity tests, training began on the visual discrimination task. Preliminary training consisted of five trials in which an animal was forced to leave the startbox and push aside a gray card in order to enter the goalbox. On the day following preliminary training, practice began on the discrimination task (W-B). On each trial, a rat was placed into the startbox for $5 \mathrm{sec}$, during which time the Plexiglas door separating the start area from the discriminanda was lowered. After elevation of the door, the animal was given approximately $15 \mathrm{sec}$ in which to make a choice. If the rat chose the black card, a mild footshock was administered, whereas choice of the white card permitted the animal to enter the goalbox. The position of the cards, but not the plastic sleeves, was varied according to a modified Gellerman sequence, and a correction procedure was employed. The animals were given 10 trials/day, with an intertrial interval of approximately $1 \mathrm{~min}$, until a criterion of 9 correct responses in 1 day was attained. The number of errors an animal made prior to the day it reached criterion constituted the measure of learning ability.

Two days after completion of the visual discrimination task and prior to the beginning of training on the olfactory discrimination task, each animal was placed on a schedule designed to reduce its weight to approximately $80 \%$ of the initial amount. The animal was weighed, then its food supply was reduced gradually until daily weighings revealed a $20 \%$ weight loss. Approximately 1 week was needed for all animals to achieve this weight loss.

Preliminary training consisted of a gradual shaping procedure in which rats were trained to push aside gray cards covering the reward wells in the small animal WGTA. A 45-mg Noyes pellet was placed in each well and shaping continued until an animal 
pushed aside a gray card and ate the pellet within 1 min on at least five consecutive trials.

In order to insure that visual cues were not employed, all rats were enucleated prior to discrimination training. This consisted of pressing the tips of blunt surgical scissors around the orbit of the eye, resulting in extrusion of the eyeball. The optic nerve and eye-muscle attachments were cut, and a cotton swab that had been soaked in alcohol was applied to the resulting lesion.

Each animal was given 2 days to recover, and was trained to push the white card and to avoid the black stimulus. Both wells were baited with one Noyes pellet on each trial, and a small wedge was placed behind the black card to prevent uncovering of the well. The noncorrection method was used primarily with occasional correction trials given to maintain responding. Discrimination training consisted of 10 trials per day with an intertrial interval of $1 \mathrm{~min}$. Animals were trained to a criterion of 9 correct responses in 1 day, a response being defined as any detectable deflection of a stimulus card. The position of the positive and negative cards was varied according to a modified Gellerman sequence.

\section{Results and Discussion}

An analysis of handling characteristics was made by comparing the 5-day totals for each animal from the two groups. By this measure, Group KNO animals were significantly less reactive than NKNO animals $(\mathrm{U}=6.5, \mathrm{p}=.032)$. The means were, for Group KNO, 1.83, and for Group NKNO, 3.83. Despite the significant difference in handling scores, all animals were relatively easy to handle, with a maximum score of 3 for an animal in Group KNO and 7 in Group NKNO, while the maximum possible score was 25 . Thus, nonkillers actually showed greater reactivity than killers, a finding which disagrees with Nováková et al. (1974). However, both scores (means) were extremely low, and because of this lack of reactivity on the part of both groups, little evidence for a valid difference between killers and nonkillers on emotionality was found, a finding which is in agreement with McCabe and Thorne (1976) and Thorne et al. (1975).

When comparison was made of the 5-day activity scores in the open field, the two groups were found to be significantly different $(U=4.5, p<.05)$. The means for the two groups were 111.83 for Group KNO and 84.33 for Group NKNO. Thus, killers exhibited a significantly greater amount of horizontal openfield activity, a finding which agrees with Nováková et al. (1974).

Rearings between the groups were nonsignificant and very similar: $\mathrm{KNO}, \overline{\mathrm{X}}=27$; NKNO, $\overline{\mathrm{X}}=24$. Since each animal was in the apparatus for a total of only $5 \mathrm{~min}$, little evidence for habituation was found.

The two groups did not differ significantly on the learning of the brightness discrimination task, and the mean number of errors to criterion was very similar for each group (Group NKNO, $\bar{X}=16$; Group KNO, $\bar{X}=16.33$ ). This supports the results obtained by Thorne et al. (1975), but disagrees with the statement by Nováková et al. (1974) that "killers are less capable of learning or remembering."

Due to death or untrainability, the data from three rats were not included in the analysis of olfactory learning ability. The number of subjects in each group actually completing training was: Group NKNO, four; Group KNO, five. The two groups did not differ significantly on the learning of the olfactory discrimination task. The average number of errors was 59 for Group NKNO (range: 29-93) and 69.2 for Group KNO (range: 41-92). Once more, these findings contradict the report by Nováková et al (1974) that killers are not as capable of learning as nonkillers.

\section{GENERAL DISCUSSION}

In contrast to many previous reports (e.g., Karli et al., 1969; Malick, 1970; Thorne et al., 1973, 1974), OB damage in Experiment 1 did not result in a significant increase in muricide by nonkillers. In addition, no evidence was found for a decrease in muricide by killers receiving $O B$ damage, a finding reported by Bandler and Chi (1972) and suggested by the results of Thompson and Thorne (1975).

One explanation for the lack of effect of $O B$ damage on muricide in the present experiment is that to classify an animal as a killer or nonkiller it was necessary to give it a muricide test. The initial muricide test gave nonkillers practice in "nonkilling." Thus the rats were not naive with respect to experience with mice as contrasted with most of the studies mentioned above in which naive rats were used. It has been demonstrated that previous exposure to mice in a nonkilling situation decreases the probability of subsequent killing (Denenberg et al., 1968; Myer, 1969). The killers, due to exposure to mice in a killing situation, continued to kill on later tests despite the OB damage. Thus, it would seem that OB damage lost its effectiveness due to the rats' experience in killing or nonkilling situations.

The length of the muricide test could also have contributed to the results of Experiment 1. A 30-min test was used, and rats not killing in that time were categorized as nonkillers. However, a longer test would probably have yielded more killers. Rats requiring more than $30 \mathrm{~min}$ to kill might be more susceptible to the effects of OB lesions and in other respects behaviorally different from animals exhibiting brief killing latencies.

In order to test the hypothesis that "hesitant" killers react differently to the effects of $O B$ damage than animals that kill promptly, the animals in Group KOB were dichotomized into those that killed in less than $15 \mathrm{~min}$ and those taking longer than $15 \mathrm{~min}$ to kill on the first test. Of the six rats taking 
less than 15 min to kill initially, all killed following OB damage. In contrast, three of four rats taking more than 15 min to kill initially failed to kill after OB removal. This difference is significant $(p=.033$, Fisher exact probability test).

The results of Experiment 2 disagree with the study by Nováková et al. (1974), who found killers to be more emotional and less able to learn than nonkillers. In our study, despite low scores by both groups, nonkillers demonstrated more reactivity to handling than killers. In agreement with Nováková et al., killers in this study exhibited a greater amount of horizontal open-field activity than nonkillers. Nováková et al. interpreted this finding as indicating lack of ability to habituate exploratory behavior. Another possible interpretation is that killer rats spend more time in exploration because of a lessened tendency to freeze in a novel situation, i.e., because they are less reactive than nonkillers.

On learning tasks, the two groups showed no significant differences. This supports the results of Thorne et al. (1975) and is in opposition to the Nováková et al. (1974) report.

The present study used natural killers and nonkillers, as did Nováková et al. (1974). Thus, we conclude that the discrepancies between McCabe and Thorne (1976) and Thorne et al. (1975), on the one hand, and Nováková et al., on the other, were not caused by our previous use of "induced" killers.

In summary, we found that $O B$ damage has little effect on the muricidal tendencies of experienced killers and nonkillers. Furthermore, killers do not appear to be more reactive or emotional than nonkillers; rather, the opposite may be true. Finally, we found no evidence that killers and nonkillers differ in learning ability.

\section{REFERENCES}

Bandler, R. J., \& CHI, C. C. Effects of olfactory bulb removal on aggression: A reevaluation. Physiology and Behavior, 1972, 8, 207-211.

Denenberg, V. H., Paschke, R. E., \& Zarrow, M. X. Killing of mice by rats prevented by early interaction between the two species. Psychonomic Science, 1968, 11, 39.

Karli, P., Vergnes, M., \& Didiergeorges, F. Rat-mouse interspecific aggressive behavior and its manipulation by brain ablation and by brain stimulation. In S. Garattini \& E. B. Sigg (Eds.), Aggressive behavior. New York: Wiley, 1969.

KING, F. A. Effects of septal and amygdaloid lesions on emotional behavior and conditioned avoidance responses in the rat. Journal of Nervous and Mental Diseases, 1958, 126, 57-63.

Knutson, J. F., \& Hynan, M. T. Predatory aggression and irritable aggression: Shock induced fighting in mouse-killing rats. Physiology and Behavior, 1973, 11, 113-115.

MALICK, J. B. A behavioral comparison of three lesion-induced models of aggression in the rat. Physiology and Behavior, $1970,5,679-681$.

McCabe, J. P., \& Thorne, B. M. Colony differences and behavior in Long-Evans rats. Bulletin of the Psychonomic Society, 1976, 7, 509-512.

MYER, J. S. Early experience and the development of mousekilling by rats. Journal of Comparative and Physiological Psychology, 1969, 67, 46-49.

MYER, J. S. Experience and the stability of mouse killing by rats. Journal of Comparative and Physiological Psychology, 1971, 75, 264-268.

MYER, J. S., \& Whrte, R. T. Aggressive motivation in the rat. Animal Behaviour, 1965, 13, 430-433.

Nováková, V., Flandera, V., \& Sandritter, W. Aggressive rats: Some properties of learning, memory and of the limbic system. Pharmacology Biochemistry and Behavior, 1974, 2, 729-733.

Rollin, A. R., Shepp, B. E., \& Thaller, K. E. A modified Wisconsin General Test Apparatus for the rat. American Journal of Psychology, 1963, 76, 500-502.

Thompson, M. E., \& Thorne, B. M. The effects of colony differences and olfactory bulb lesions on muricide in rats. Physiological Psychology, 1975, 3, 285-289.

Thorne, B. M., Aaron, M., \& Latham, E. E. Effects of olfactory bulb ablation upon emotionality and muricidal behavior in four rat strains. Journal of Comparative and Physiological Psychology, 1973, 84, 339-344.

Thorne, B. M., Aaron, M., \& Latham, E. E. Olfactory system damage in rats and emotional, muricidal, and rat pup killing behavior. Physiological Psychology, 1974, 2, 157-163.

Thorne, B. M., \& O'Brien, A. L. The use of olfactory cues in solving a visual discrimination task. Behavior Research Methods \& Instrumentation, 1971, 3, 240.

Thorne, B. M., Patterson, A. S., \& Topping, J. S. Behavioral differences between killer and nonkiller rats. Bulletin of the Psychonomic Society, 1975, 6, 152-154.

Thorne, B. M., \& Thompson, M. E. The effect of different types of mice upon muricidal behavior in the Long-Evans rat. Physiological Psychology, 1976, 4, 238-246.

Vergnes, M., BoEHRER, A., \& KARLI, P. Interspecific aggressiveness and reactivity in mouse-killing and nonkilling rats: Compared effects of olfactory bulb removal and raphe lesions. Aggressive Behavior, 1974, 1, 1-16.

(Received for publication September 20, 1977; accepted October 27, 1977.) 